\title{
On Metabolism: Ensuring Our Health Care System Remains "Ready-to-Hand"
}

\author{
Brett Schrewe $^{1}$ \\ ${ }^{1}$ The University of British Columbia Faculty of Medicine
}

August 17, 2020

Title

On Metabolism: Ensuring Our Health Care System Remains "Ready-to-Hand"

Running Title (less than 50 characters)

On Metabolism

\section{Author}

Brett Schrewe MDCM, MA, FRCPC

\section{Corresponding Author}

Brett Schrewe MDCM, MA, FRCPC

e: brett.schrewe@cw.bc.ca

t: 778 (998)1066

Address

Centre for Health Education Scholarship, Faculty of Medicine

The University of British Columbia

P. A. Woodward Instructional Resources Centre (IRC)

429 - 2194 Health Sciences Mall

Vancouver, BC Canada V6T 1Z3

\section{Institutional Affiliations}

Brett Schrewe MDCM, MA, FRCPC

Clinical Assistant Professor, Department of Pediatrics, Faculty of Medicine

The University of British Columbia

Victoria, BC, Canada

Main Text

The current coronavirus pandemic has threatened the lives of the most vulnerable, ravaged global economic systems, and altered patterns of everyday life in ways that even at the beginning of the year would have been unrecognizable. At the same time, it has also reinforced the importance of reliable and robust health care systems as key threads of the social fabric. Here in Canada, like many other countries, one need only 
look back upon the frenetic shifts in governmental priorities, the media attention directed onto public health officials, the countless times when we have been exhorted to flatten the curve to give our health care system a chance, and widespread public support of health care workers that have characterized these last few months. These instances remind us that as "the maintenance of human life and the reduction of physical suffering have become paramount" ${ }^{1}$ in Western societies, health care systems are popularly viewed as powerful agents of deliverance holding the line against the virus and the anxieties of sickness, finitude, and death that travel with it.

Until there is a real threat of that social fabric unraveling, however, one might not consider what comprises the threads that constitute it. While I draw upon the Canadian example here, the particularities of its experience have significant parallels in contexts beyond its borders. Prior to the coronavirus pandemic, we might have considered our health care system, despite its imperfections, ${ }^{2,3}$ one that operated more or less seamlessly, or "ready-to-hand". ${ }^{4}$ That is to say, the relationships and interactions that enabled our system to deliver health care in spaces such as acute care hospitals worked such that their complexity was not readily apparent on an everyday level. Health care professionals could be easily forgiven for not consciously recognizing the myriad nuances of the tapestry in which they provided safe and high-quality patient care.

The pandemic's effects in these recent weeks, however, have changed all of that. Stresses upon the health care system have thrown a spanner in the gears of our reasonably well-oiled machine, threatening to make our system "unready-to-hand". Yet, paradoxically, it is in anxious moments of crises like these where fluid activity slows down to the point that we can consciously distinguish the myriad elements of our system - including those easily overlooked - and how they actually articulate. ${ }^{4}$ Otherwise put, the effects of the pandemic have rendered our health care system "present-at-hand": a disorienting rupture in our usual taken-for-granted patterns, of course, but also an opportunity to better understand the collection of roles, relationships, and interactions that are principally used to realize health care.

Significant stress upon the overall network of the health care system has congealed within one of its principal nodes, the acute care hospital. Placing it under the microscope, we know that its ability to function is contingent upon the determined efforts of medical personnel such as nurses, physicians, and respiratory therapists. Yet it is now glaringly evident that non-medical workers are also indispensable in realizing health care within its walls. For example, it is impossible for those of us with predominantly clinical duties to assess or care safely for someone with coronavirus without an appropriately cleaned room. It is impossible to safely enact health care without having necessary personal protective equipment (PPE), hand sanitizer, and equipment wipes restocked outside patient rooms and in emergency departments. It is impossible to have the scripted choreography of efficient patient flow from triage to emergency department to CT to intensive care without the work of porters. That PPE is available to be worn in the first place necessitates that it be made ready for distribution by those who staff the hospital's receiving department. That a sufficient number of ventilators are available to care for those needing advanced respiratory support demands not just sufficient production, but the skill of those in hospital engineering and maintenance departments able to service these pieces of lifesaving equipment at a time when they are in recurrent usage. The information technology infrastructure and those who maintain the enormous demands upon it render results and necessary patient care data available on a continuous basis. In our current reality, these workers, like other essential services, deserve the full gratitude of society.

Yet it is not just the complexity of the networks of personnel within the hospital that have been illuminated. While initial concerns about a massive shortage in ventilators and a critical steady supply of PPE have now abated to some degree, those needs cast an unexpected light upon the sustainability of the outside supply chains that power the hospital's daily health care activities. In large part due to laudable efforts made by domestic companies to re-purpose their manufacturing infrastructure and governmental coordination, Canada has now moved into a phase where its ability to maintain PPE supplies domestically has grown dramatically. ${ }^{5}$ Yet the process of getting to this point was a massive scramble at a time when the potential for miscommunication and missteps with catastrophic consequences was high. Further, the domestic supply line is still not yet robust enough to avoid the need to get in line with the rest of the world for internationally- 
based PPE suppliers or to mitigate the effects of political decisions made by other countries upon PPE orders that had already been placed. ${ }^{6,7}$

Some countries now find themselves standing in the midst of a first wave, while others are imminently bracing for a second. Here, we are more or less between waves, with a small amount of time to reflect upon the lessons of the last few months before we find ourselves quite likely back in the maelstrom. Rather than waiting - again - for the point in which our health care system is in danger of being overwhelmed and our society left vulnerable, we need to consider broader ways of thinking that may attend proactively to the complexities that have been revealed by coronaviral stresses. This becomes all the more important when we recognize that, like many other jurisdictions, our system's optimal functioning demands an alignment between myriad stakeholders, including federal funding and standards setting, provincial administration, and delivery through multiple health authorities and a multitude of different hospitals, all of which have different considerations and responsibilities in realizing our social right to health care.

Drawing upon metabolism offers a shared conceptual frame that is accessible to those who attend primarily to health care in a clinical fashion, those who consider the system's administration, and those who are responsible for financial and material inputs and outputs. Originating as a physiological concept in nineteenth-century organic chemistry, ${ }^{8}$ metabolism has also been used as a philosophical approach to consider the relationships between humans, the natural environment, and social phenomena. ${ }^{9}$ Highlighting process, flow, and dynamic change ${ }^{10}$ a metabolic view suggests that the solid appearance of the physical plant of the acute care hospital belies its reality as a locus of an ever-moving complex set of interactions and patterns that reproduce themselves on a continuous basis. As such, the reassuring stable appearance of day-to-day appearance of health care delivery is actually a dynamic equilibrium, a constant balance to which we must attend.

Appreciating that there is "an inside and an outside" 10 to the acute care hospital organism, metabolic thinking transcends the walls separating its inner workings and its outer supply chains necessary for its ongoing activity. Specifically, it enables those who design health care systems, develop policy, administer health authorities, and manage hospitals to align their considerations in order to consider more widely how health care is enacted, how personnel come together to realize it, which materials are necessary to sustain it, and which effects - both intended and unintended - may be produced as a result. As such, discussions on topics as wide-reaching as providing just living wage and benefit offerings commensurate with the essential roles of non-medical workers, ensuring the safety of working conditions during pandemics, rendering the supply system far more resilient to global disruptions, and guaranteeing the material and social sustainability of the health care system writ large may be made part of a broader and ongoing proactive conversation rather than thwarted by jurisdictional or philosophical silos.

COVID-19 has consumed much of the oxygen of 2020 thus far, burning through norms of the global order with a ferocity and a velocity that has left governments and institutions from across the world struggling to catch their breath and respond in an effective and cohesive manner. In placing our health care systems under duress, however, it has allowed us to better understand their complexities and illuminated key components that have been, until now, overshadowed. As the smoke slowly begins to clear, a metabolic approach gives us an opportunity to re-consider how we may attend to the myriad interlocking pathways of health care systems in a sustainable and proactive manner, such that our society and its leaders at all levels are able to more readily respond to both subsequent waves and other major events no doubt awaiting us in the future.

\section{References}

1. Good BJ. Medicine, Rationality and Experience: An Anthropological Perspective . Cambridge, New York: Cambridge University Press; 1994.

2. Schneider EC, Sarnak DO, Squires D, Shah A, Doty MM. Mirror, Mirror 2017: International comparison reflects flaws and opportunities for better US health care. New York, USA: The Commonwealth Fund 2017.

3. Canadian Institutes of Health Information. OECD interactive tool: interactive comparisons. [Internet]. Ottawa: The Institute [cited 15 April 2020]. Available from https://www.cihi.ca/en/oecd-interactive- 
tool-international-comparisons.

4. Heidegger M. Being and Time. Stambaugh J, translator. Albany, USA: SUNY Press 1996.

5. Public Services and Procurement Canada. Supplying Canada's response to COVID-19. https://www.tpsgc-pwgsc.gc.ca/comm/aic-scr/provisions-supplies-eng.html. Published 7 August 2020. Accessed 12 August 2020.

6. Cecco L, Borger J. Trump and 3M reach deal to allow N95 face masks to be exported to Canada. The Guardian [Internet]. https://www.theguardian.com/world/2020/apr/06/us-blocks-face-masks-canadan95-protection-equipment. Published 7 April 2020. Accessed 15 April 2020.

7. Dyer E. The great PPE panic: How the pandemic caught Canada with its stockpiles down. Canadian Broadcasting Corporation. https://www.cbc.ca/news/politics/ppe-pandemic-covid-coronavirusmasks-1.5645120. Published 11 July 2020. Accessed 12 August 2020.

8. Von Liebig J. Organic Chemistry in its Application to Agriculture and Physiology. Gregory W, translator. London: Taylor and Walton; 1842.

9. Foster JB, Clark B. Marx's ecology and the left. Monthly Review2016;68(2):1-25.

10. Landecker H. The metabolism of philosophy, in three parts. In: Malkmus B, Cooper I, eds. Dialectic and Paradox: Configurations of the Third in Modernity . Bern: Peter Lang; 2013:193-224. 